\title{
XUVENTUDE E PATRIMONIO. O EXEMPLO DO CAMPO INTERNACIONAL DE TRABALLO DAS ILLAS CIES
}

\author{
MANUEL GARCÍA VALDEIRAS
}

\begin{abstract}
Resumo
No sur da Illa do Medio do arquipélago das Cíes, localízase o "Castro das Hortas», inventariado dende 1992. A Dirección Xeral de Xuventude encargou un proxecto para a posta en valor do xacemento, utilizando ós voluntarios do Campo

Internacional de Traballo das Illas Cíes.
\end{abstract}

\begin{abstract}
On the South of one of the islands of the Cies archipelago called Medio Island, there is an ironaged settlement, "Castro das Hortas», inventoried since 1992. A project was entrusted by the «Dirección Xeral de Xuventude» to evaluate tehe site, using the International Labour Camp voluntaries of the Cies Islands.
\end{abstract}

\section{Palabras Clave}

Castros, xuventude, patrimonio. 
$\mathrm{E}$ ste artigo é o desenrolo de dúas comunicacións, a primeira presentouse no Congreso «A xuventude e o Medioambiente» organizado pola Xunta de Galicia $^{1}$ en Portomarín entre o 18 e 19 de Setembro de 2002, baixo o título de «Actuacións da xuventude no patrimonio Cultural», en colaboración con Rubén Mateos López, xerente do campo Internacional de Traballo das Illas Cies. A segunda comunicación presentouse nos «Encontros galegos de arqueoloxía» organizados pola Xunta de Galicia e o CSIC o 25 de abril de 2003, baixo o mesmo título que o presente traballo.

\section{INTRODUCCIÓN}

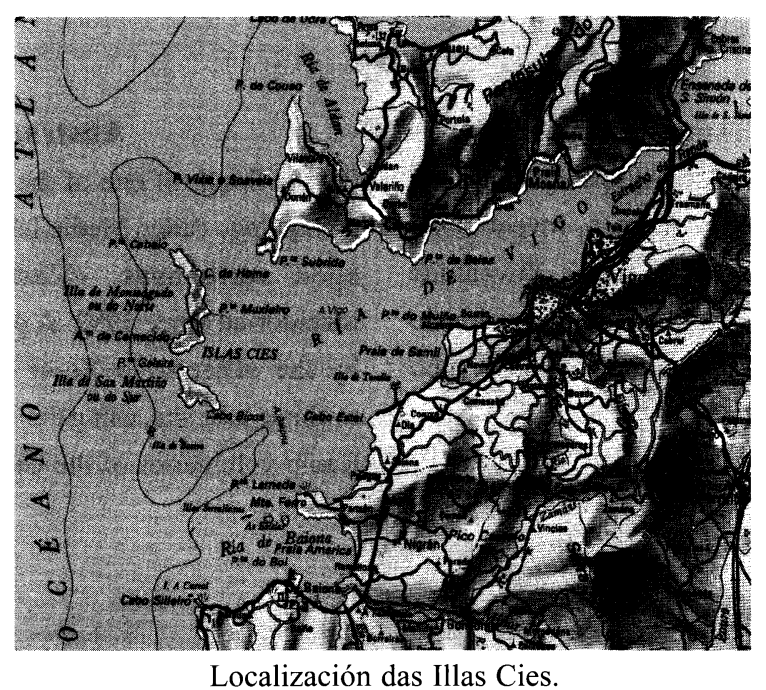

No extremo sur da Illa do Medio do pequeno archipielago das Illas Cies, concretamente na ladeira entre o Faro Grande e o Faro Pequeño, localízase un xacemento arqueolóxico catalogado como castro pola Dirección Xeral de Patrimonio Cultural dende o ano $1992^{2}$. A Dirección Xeral de Xuventude encargounos un proxecto para rendabiliza-lo antedito castro, coñecido como «Castro das Hortas», utilizando para

\footnotetext{
${ }^{1}$ Consellería de Familia e Promoción do Emprego, Muller e Xuventude e a Consellería de Medio Ambiente.

${ }^{2}$ GA36057080.
}

Cuadernos de Estudios Gallegos, Tomo LI, Fascículo 117, Santiago 2004. (Págs. 115 - 132) 
elo os voluntarios do Campo Internacional de Traballo das Illas Cies, rapaces de toda Europa de entre 18 e 30 anos, repartidos en catro quendas de 30 participantes. O Campo de Traballo estivo adicado ata o momento a funcións de mantemento do medio ambiente. Tal como recolle a lei o patrimonio arqueolóxico forma parte tamén do patrimonio ambiental polo que o novo rumbo do campo de traballo non se debe considerar nunca como un cambio de interés con respecto o medio ambiente senón como un intento de centrarse nunha parte determinada dese patrimonio ambiental, por certo unha parte que era unha das máis descoñecidas e desatendidas do agora parque nacional. Coa actividade arqueolóxica o Campo de Traballo sería protagonista dun proxecto propio sen por elo descuida-los servicios de medio ambiente, colaborando así no cuidado do patrimonio natural das Illas Cies. Ante a solicitude da Dirección Xeral de Xuventude propuxemos un proxecto a 6 anos no que era imprescindible implicar ás consellerías de Medio Ambiente e Cultura.

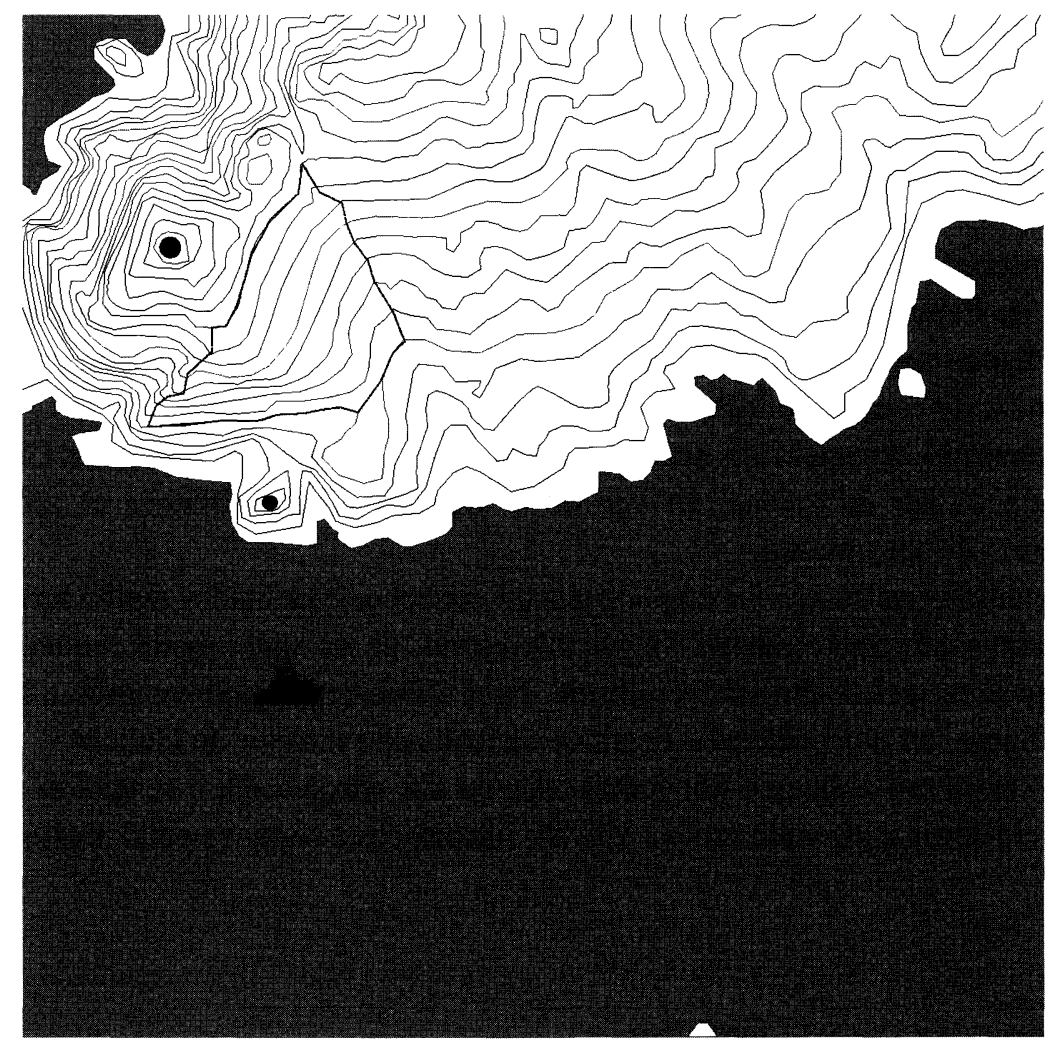

Extensión do xacemento entre o dous faros. 
O proxecto piloto de rendabilización socio-cultural do Castro das Hortas ocuparía 6 campañas de dous meses, as correspondentes os meses de actividade do Campo de Traballo. A $1^{\text {a }}$, que foi a do verán de 2002, adicaríase á limpeza da vexetación do castro cuberto por un espeso monte baixo e acacias que o convertían nun autentico «mato grosso», e o levantamento topográfico do xacemento. $\mathrm{Na} 2^{\mathrm{a}}$ campaña revisouse o catalogo de xacementos co fin de obter unha carta arqueolóxica exhaustiva das illas do Norte e o Medio e repasouse a limpeza do castro. Na $3^{\mathrm{a}}, 4^{\mathrm{a}}$ e $5^{\mathrm{a}}$ campañas procederíase á escavación en área do xacemento para na $6^{\circ}$ e última campaña proceder á consolidación de estructuras, sinalización e divulgación do xacemento, co que daríamos fin o proxecto de posta en valor. $O$ medio para conseguir os fins dese proxecto, o Campo de Traballo, era o mesmo tempo o principal obxetivo, ó servir esta nova actividade para dar un novo senso o campo, educando e sensibilizando a xuventude participante no coñecemento e respeto polo patrimonio, facéndoos sentir parte útil e importante do parque; para elo foron de gran axuda as visitas institucionais e o constante seguimento por parte dos medios de comunicación.

\section{O ANTECEDENTE DE «PENEDOS DO CASTRO»}

Os antecedentes deste proxecto témolos no proxecto de rendabilización sociocultural de Penedos do Castro no concello de Nogueira de Ramuín, enclavado na Ribeira Sacra ourensá. Comenzando no ano 1999, foi, que coñezamos, a primeira experiencia de campo de traballo arqueolóxico en Galicia.

O desenrolo, á espera de acabar a útima fase, é o mesmo que o de Cies, coa salvedade de ser en 4 anos en vez de 6, debido principalmente ás reducidas dimensións do xacemento.

O encargo neste caso nos veu por parte do concello, necesitados dunha nova motivación para o campo de traballo e a par interesados en ter xacementos arqueolóxicos visitables para incluir en rutas culturais. Non esquezamos que estamos a falar da Ribeira Sacra, un dos principais destinos turísticos do interior de Galicia.

Este castro era coñecido por localizarse na súa coroa unha inscripción adicada a «Leovigildo» e datable no s. $\mathrm{VI}^{3}$. A limpeza da capa vexetal neste sector

${ }^{3}$ RODRÍGUEZ COLMENERO, 1995.

Nota: Durante o verán do 2003 non houbo campo de traballo debido á catástrofe do Prestige.

Cuadernos de Estudios Gallegos, Tomo LI, Fascículo 117, Santiago 2004. (Págs. 115 - 132) 


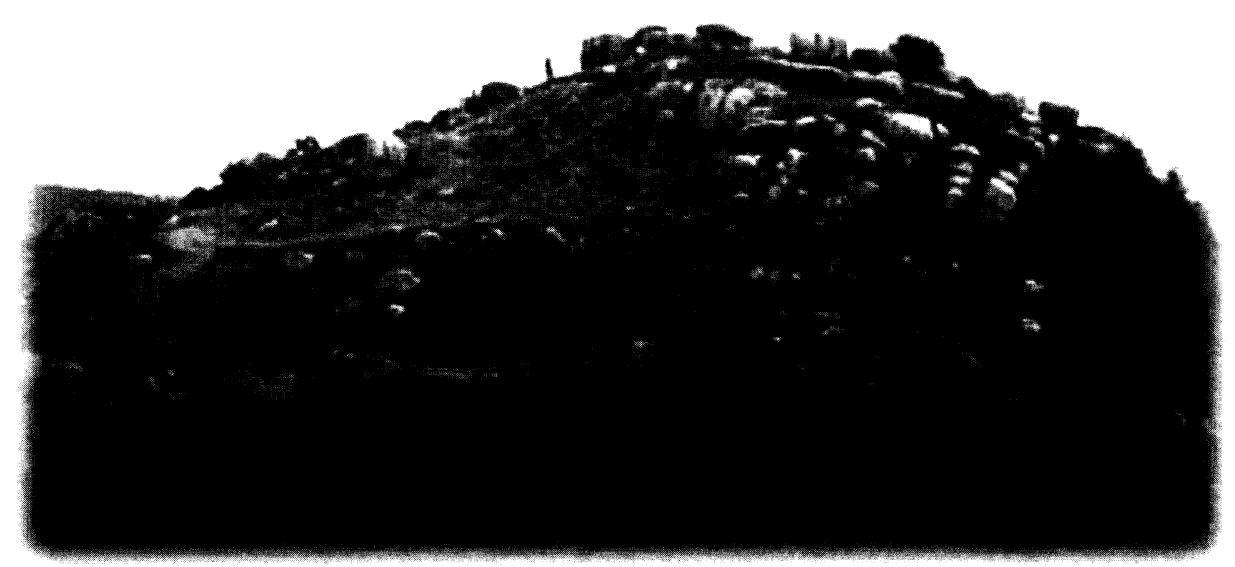

Penedos do Castro.

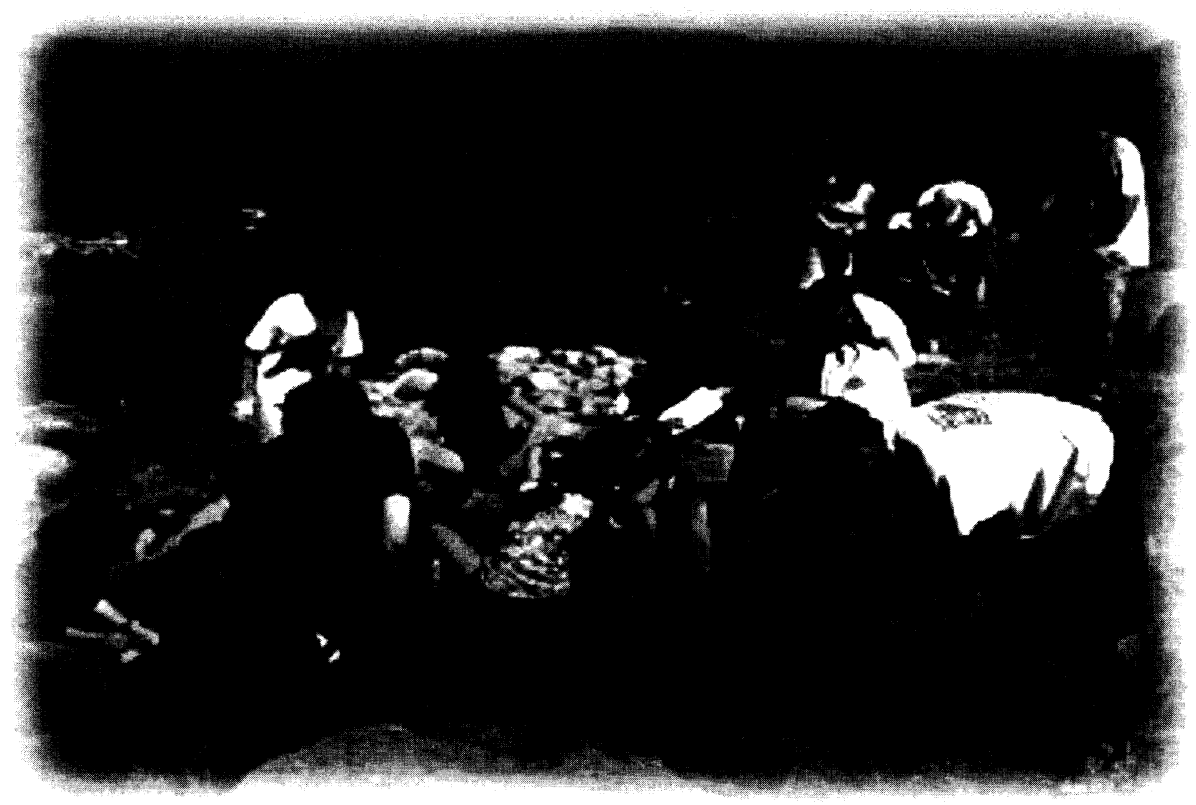

Escavación da coroa.

Cuadernos de Estudios Gallegos, Tomo LI, Fascículo 117, Santiago 2004. (Págs. 115 - 132) 
permitiunos comprobar a ausencia completa de potencia estratigráfica o que priva de fiabiliade ós materiais recollidos, que van dende cerámica castrexa ata a baixomedieval, pasando por restos de escoria de ferro e puidores. Planimétricamente aprecianse os restos da muralla que defendería este sector do xacemento e a súa entrada. A aparición de cerámica medieval parece confirmar a utilización da coroa deste castro como punto de vixiancia e control na Idade Media por parte do señor destas terras, o abade do mosteiro de Sto. Estevo de Ribas de Sil.

Fora da coroa destaca a aparición da impresionante muralla ciclópea de máis de tres metros de anchura, esta estructura defendía o acceso ó castro polo único lado non defendido naturalmente, a muralla conta cunha estructura de reforzo na cimentación. Os materias encontrados na cimentación proban a súa antigüidade que pode remontarse cando menos ós inicios da Idade do Ferro / finais da Idade do Bronce.

A funcionalidade do xacemento na Idade do Ferro sería a mesma que na Idade Media, a vixiancia e protección do asentamento que se situaría na actual localización do mosteiro. Penedos do Castro preséntasenos como un castro atípico cunha función meramente defensiva e, o mesmo tempo coa súa ocupación medieval, é un claro exemplo do proceso de «encastelamento» ${ }^{4}$.

No proxecto de «Penedos do Castro» só resta acometer a consolidación das súas estructuras e a divulgación do xacemento a través de tres instrumentos, a colocación dun cartel explicativo a entrada do xacemento cunha foto-interpretación do castro, a publicación dun folleto explicativo que inclue un poster cunha reconstrucción hipotética do xacemento e por último a súa inclusión nunha ruta de sendeirismo que parte do Mosteiro de Sto. Estevo, recentemente inagurado como Parador Nacional.

\section{DESENROLO DO PROXECTO DE CIES}

O fundamento da primeira campaña era o desbroce da capa vexetal que cubría o xacemento. Este traballo, a primiera vista sinxelo, requería un gran esforzo físico, sobre todo si temos en conta a forte pendente na que se localizan os restos e a falta de experiencia no uso de ferramentas por parte da gran maioria dos participantes. A principal arma para vencer todas estas dificultades é a motivación.

\footnotetext{
${ }^{4}$ Os resultados das actuacións neste xacemento, unha vez rematados todolos traballos, van a ser obxeto dun estudio máis detallado.
}

Cuadernos de Estudios Gallegos, Tomo LI, Fascículo 117, Santiago 2004. (Págs. 115 - 132) 


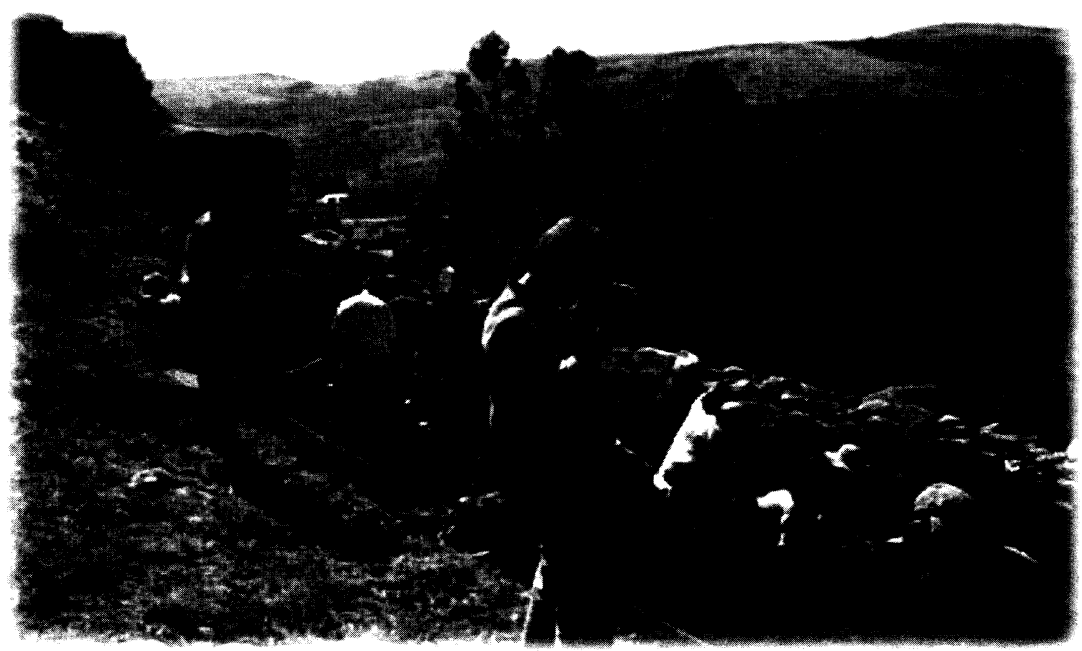

Escavación da muralla.

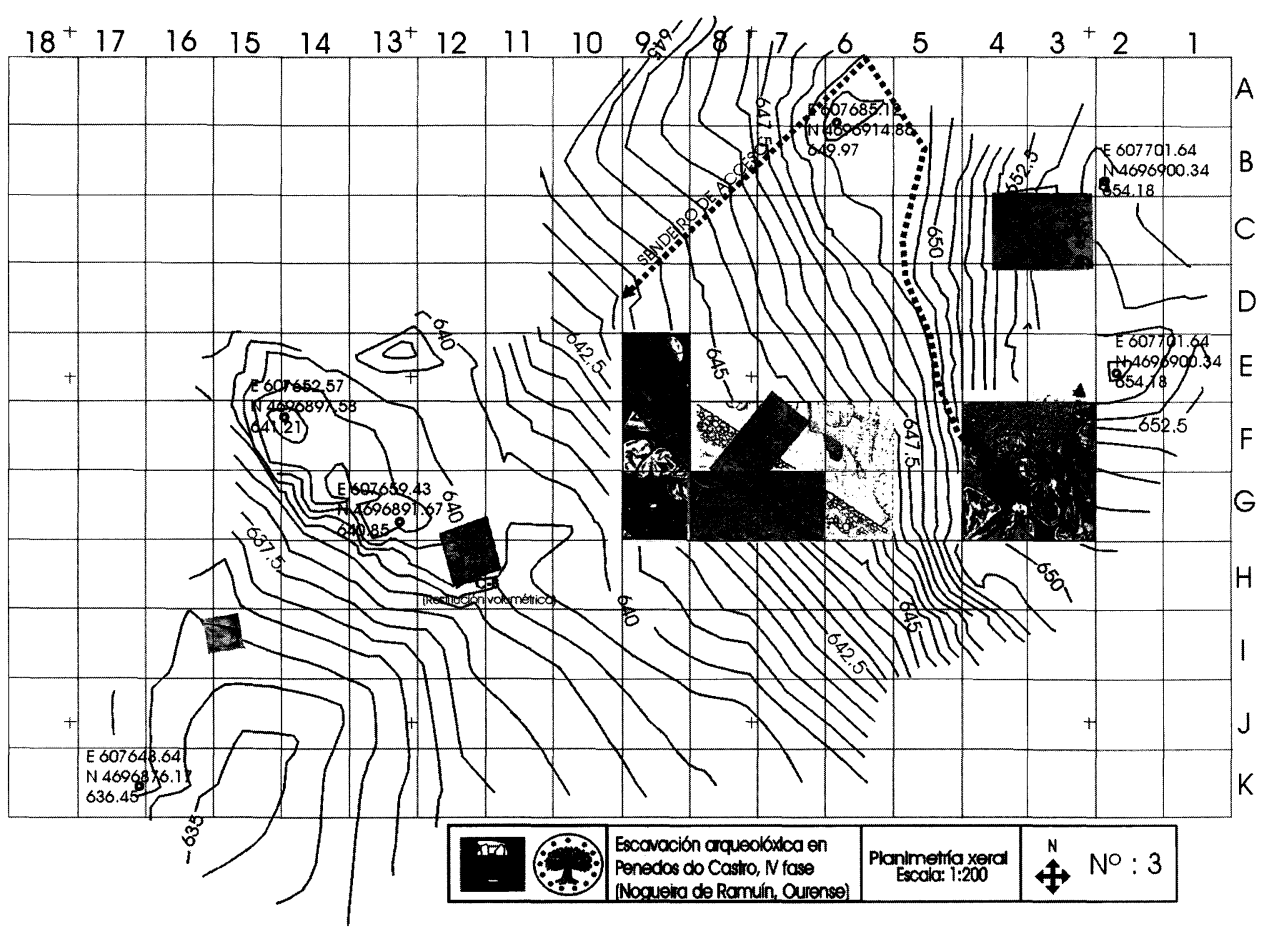

Planimetría do xacemento. 


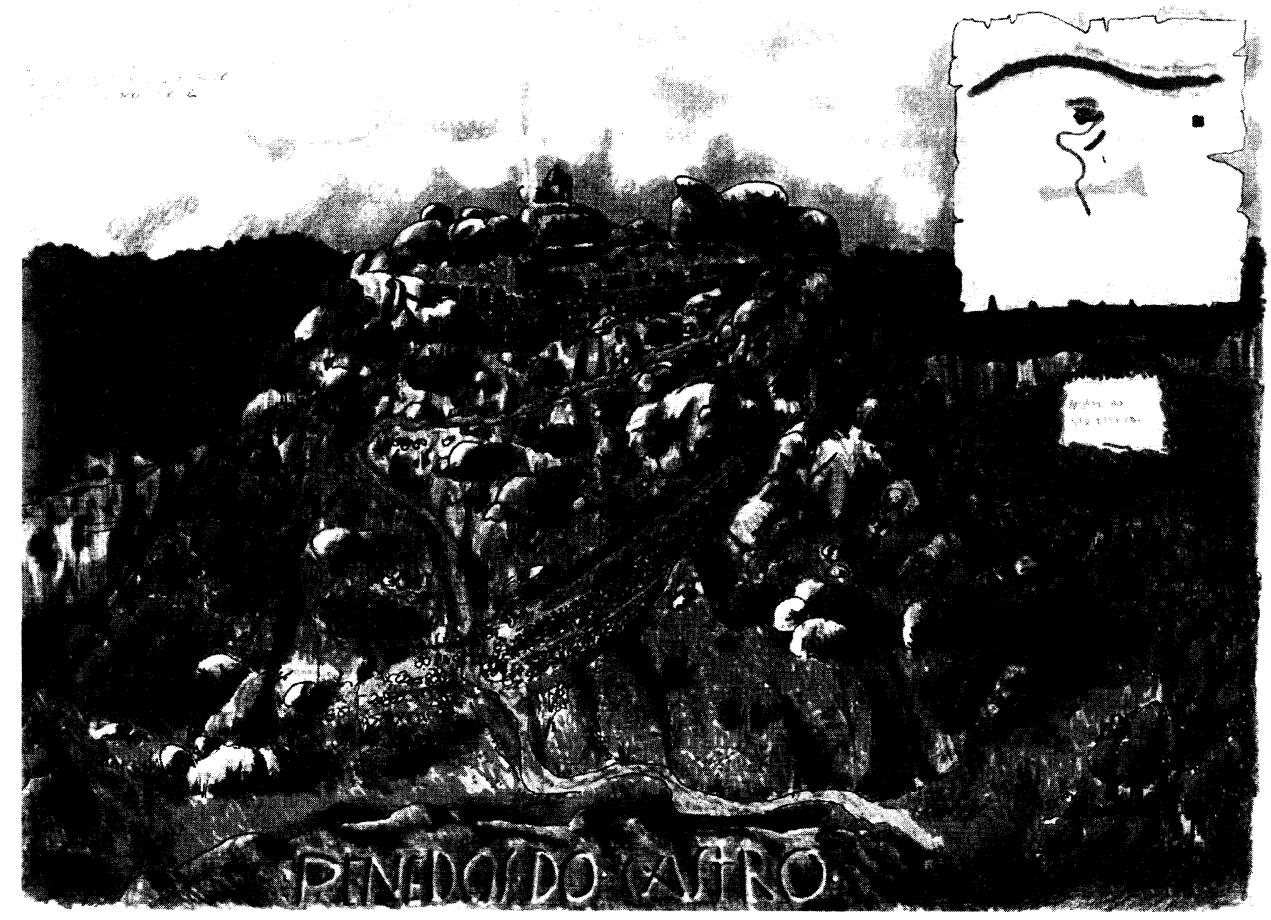

Boceto coa reconstrucción idealizada do xacemento na Idade Media.

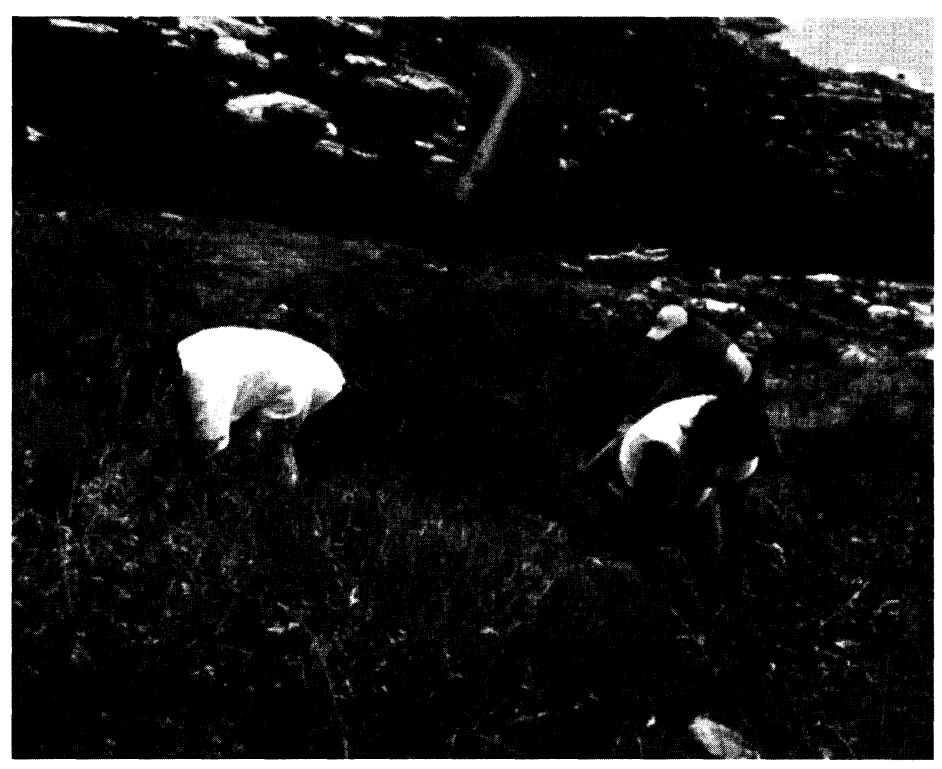

Castro das Hortas. Traballos de limpeza. 
¿Cómo se consigue esta motivación? Fundamentalmente explicando todo, cada traballo que se fai debe ter unha razón. Un exemplo: ese montón de pedras que se acaban de deixar ó descuberto son unha casa castrexa, despois de limpala os voluntarios deben deseñala en planta e alzado, e facer unha reconstrucción ideal para entende-lo significado dos restos.
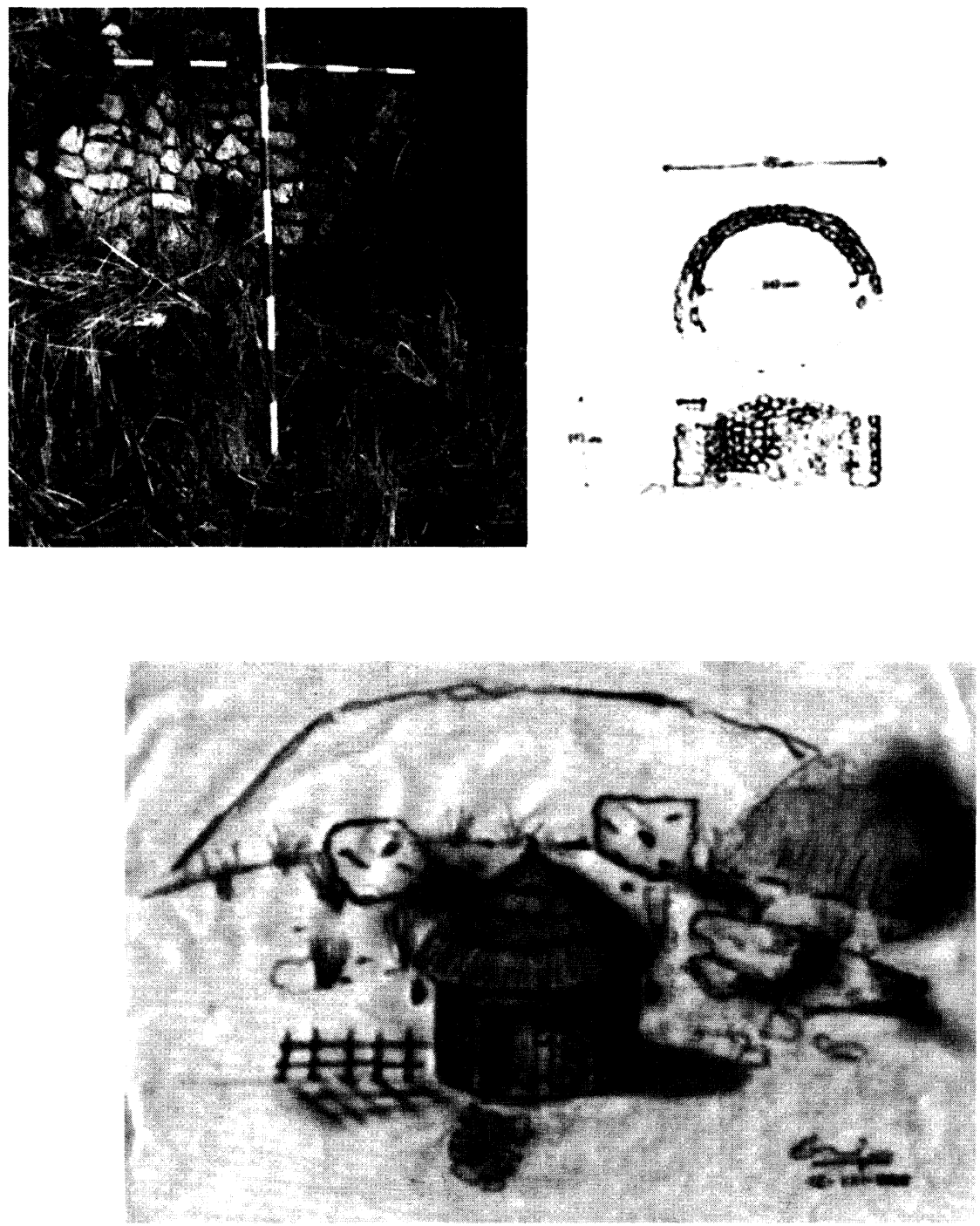

Casa castrexa. 

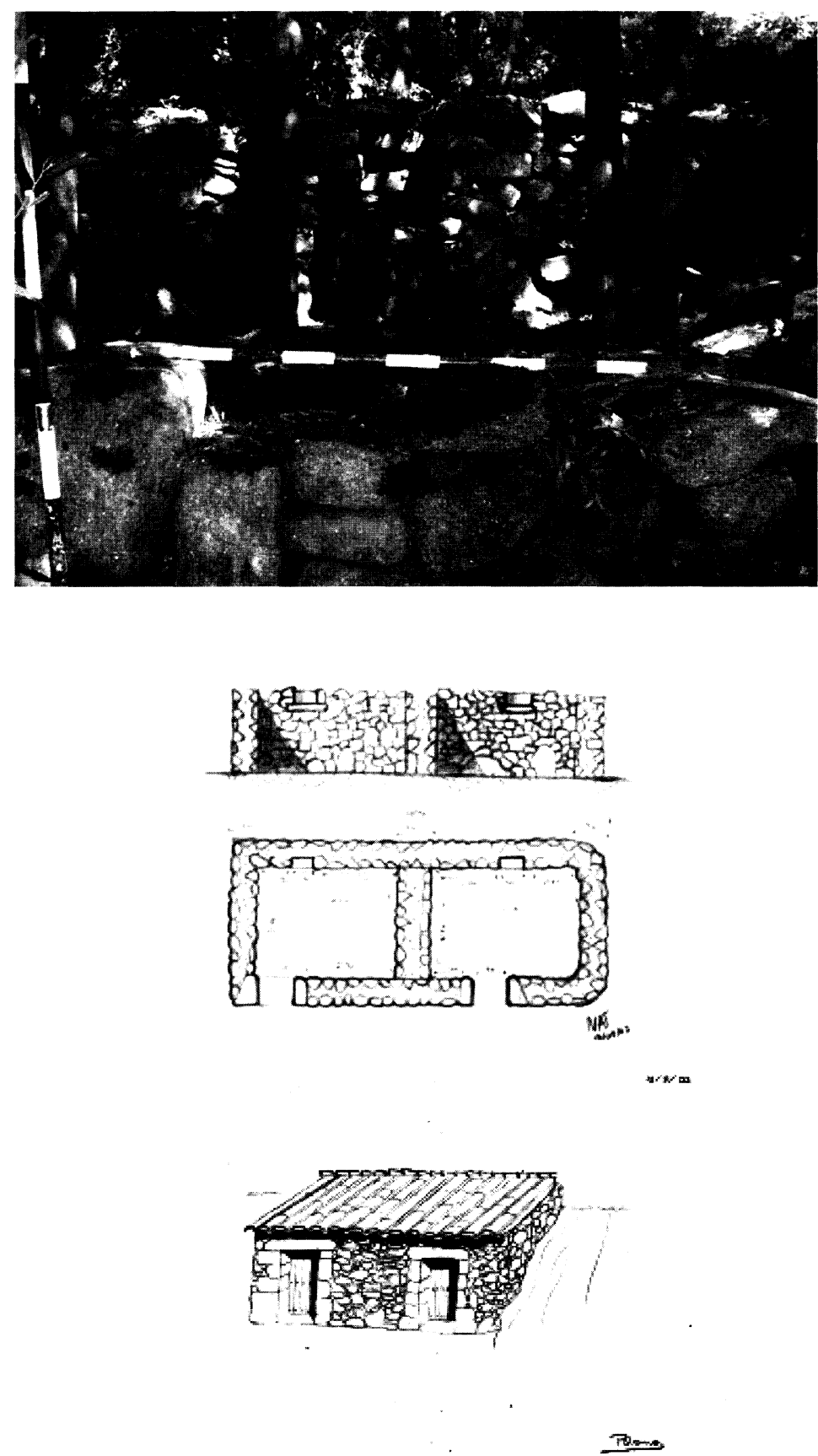

Casas dos horteláns. 
O traballo de campo complementouse con clases de deseño arqueolóxico de materiais, conferencias de temática arqueolóxica, talleres de restauración cerámica (lavado, pegado, siglado e clasificado dos fragmentos) a cargo sempre de técnicos especialistas (debuxantes, restauradores, topógrafos ${ }^{5}$ ). Como aínda non se fixeron escavacións no castro das Hortas o material tratado correspondeu a última campaña de Penedos do Castro. Este traballo que nun primeiro momento póde ser monótono debe compensarse coas debidas explicacións acerca da procedencia e clase dos materiais que estamos traballando, así como da finalidade do tratamento que lle estamos dando dentro da metodoloxía arqueolóxica. Os voluntarios deben sentirse como detectives que estudian as pezas recollidas nun xacemento como probas recollidas no lugar dun crimen, pequenas pistas que nos axudaran a desentraña-los misterios do ¿cando?, ¿cómo?, ¿porqué?, ¿quen? etc.

A pesares de intentar sacar proveito das especiais aptitudes e coñecementos dos acampados a maioría estudiantes universitarios de xeoloxía, belas artes, historia, bioloxía..., procurouse que todo o mundo pasara por tódo-los traballos, dende o duro desbroce, ó posicionamento cartográfico de estructuras ou o deseño de pezas. Con elo tratábamos de facerlles comprender que o traballo de arqueólogo pode ser duro e as veces monótono pero que tamén permite coñecer unha gran variedade de técnicas e instrumentais.

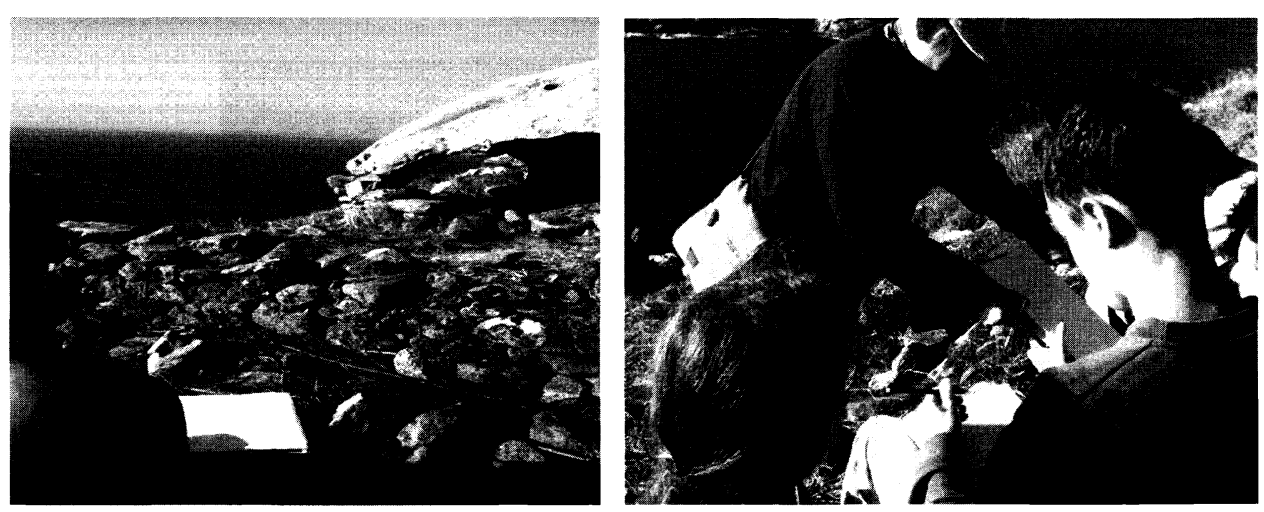

Clases prácticas de deseño arqueolóxico de campo.

${ }^{5} \mathrm{O}$ equipo arqueolóxico estivo formado por dous arqueólogos (o que suscribe e Jorge Lamas Bértolo), unha restauradora, Victoria Folgueira Fariña, e un debuxante, Francisco Boluda Barreiro, o levantamento topográfico correu a cargo da empresa GECOTOP, asemade contouse coa colaboración da arqueóloga Carmen Gómez Nistal para as conferencias. 
A pesar de centrarnos no estudio das «pedras», non podemos esquencer en ningún momento que estábamos nun Parque Nacional, cunha enorme riqueza de flora e fauna que debía ser respetada. Ademais de contar co evidente permiso de Medio Ambiente, nos asesoraron desinteresadamente biólogos e ecoloxistas, coñecedores da riqueza natural das illas. Nos orgullecemos de asegurar que ningún animal sufríu dano físico, salvo o inevitable estrés e os desplazamentos derivados da limpeza de vexetación, as escasas moreiras da ladeira foron respetadas, só temos que lamentar como «danos colaterais» os abruñeiros que nos impedían o paso ós socalcos.
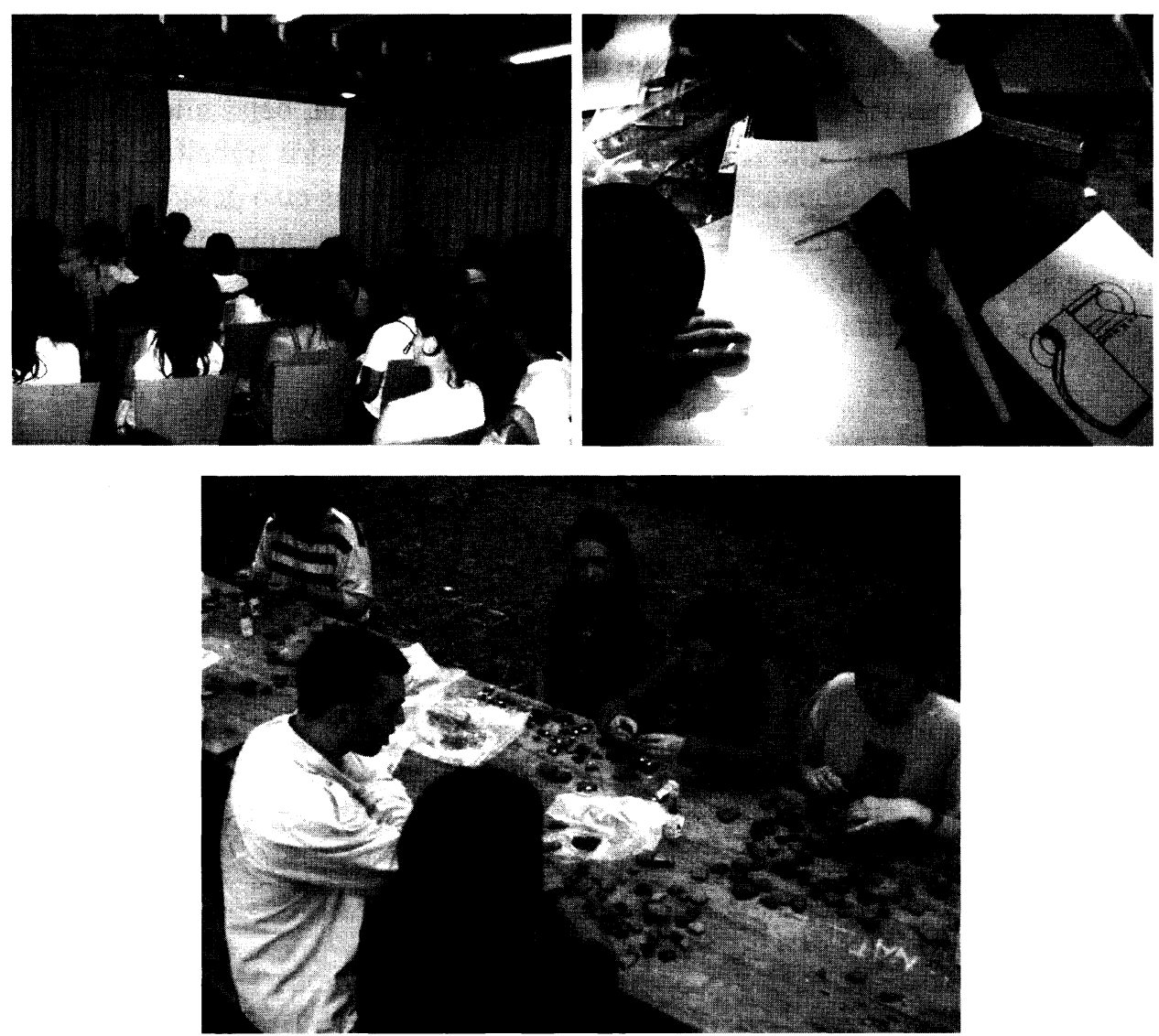

Conferencias e taller de restauración cerámica. 


\section{OBXETIVOS}

O obxetivo da rendabilización patrimonial deu o seu primeiro e imprescindible paso co desbroce do castro, pero evidentemente esto require un mantemento continuado para o cal é imprescindible a colaboración dos servicios de Medio Ambiente. Asemade faise imprescindible a consolidación de moitas estructuras, sobre todo socalcos, en condicións de inminente derrube o que fai perigoso o libre acceso dos turistas. Por último a forte pendente fai que sexa necesaria a creación dun sendeiro en zig-zag que guíe ó visitante ó mesmo tempo que facilite o transito entre as ruínas.

O principal obxetivo científico desta campaña era o levantamento topográfico, ferramenta básica para planifica-las futuras campañas de escavación, elaborouse a planimetría das estructuras visibles, cuadrículose en plano todo o sector e deixaronse estacións topográficas de referencia repartidas por todo o xacemento.
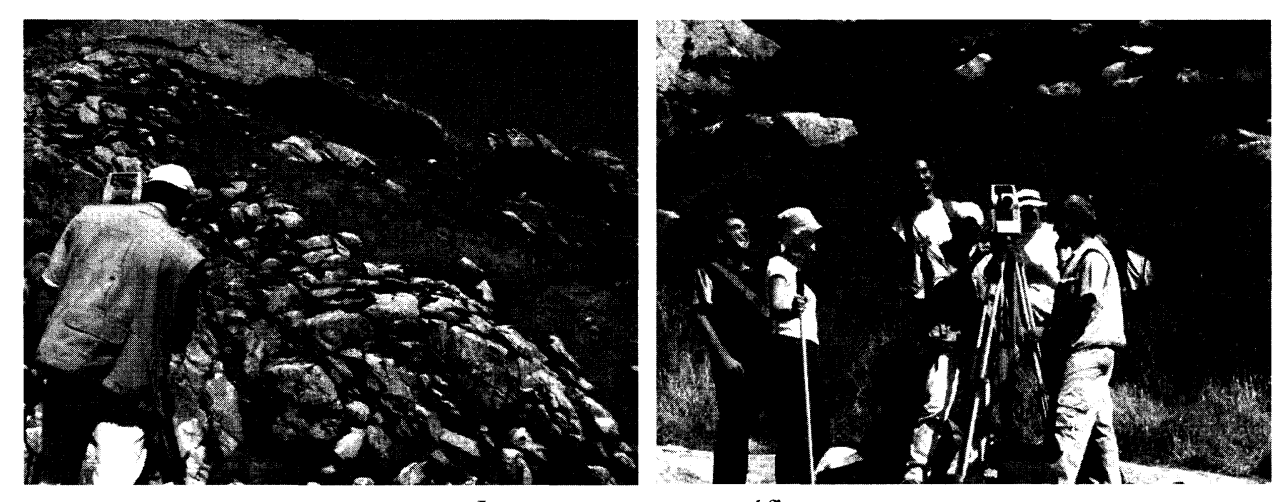

Levantamento topográfico.

A limpeza da vexetación do xacemento permitiunos clarifica-la tipoloxía do asentamento, desmentindo algúns puntos da súa ficha de catalogación como a existencia de murallas ou confirmando a súa romanización, como se insinuaba na antedita ficha. Na nosa opinión, e a vista das estructuras e do estudio do contorno inmediato do xacemento, cremos que o que temos nas ladeiras entre os dous faros da Illa do Medio, son os restos dun asentamento castrexo, posteriormente romanizado; tal afirmación fundamentase na existencia dun imponente concheiro, así como de refuxios naturais antropizados, unha casa circular e abundante material en superficie, se ben cremos que o castro propiamente dito estaría no alto que hoxe ocupa o faro grande, sendo totalmente arrasado durante a súa construcción; 

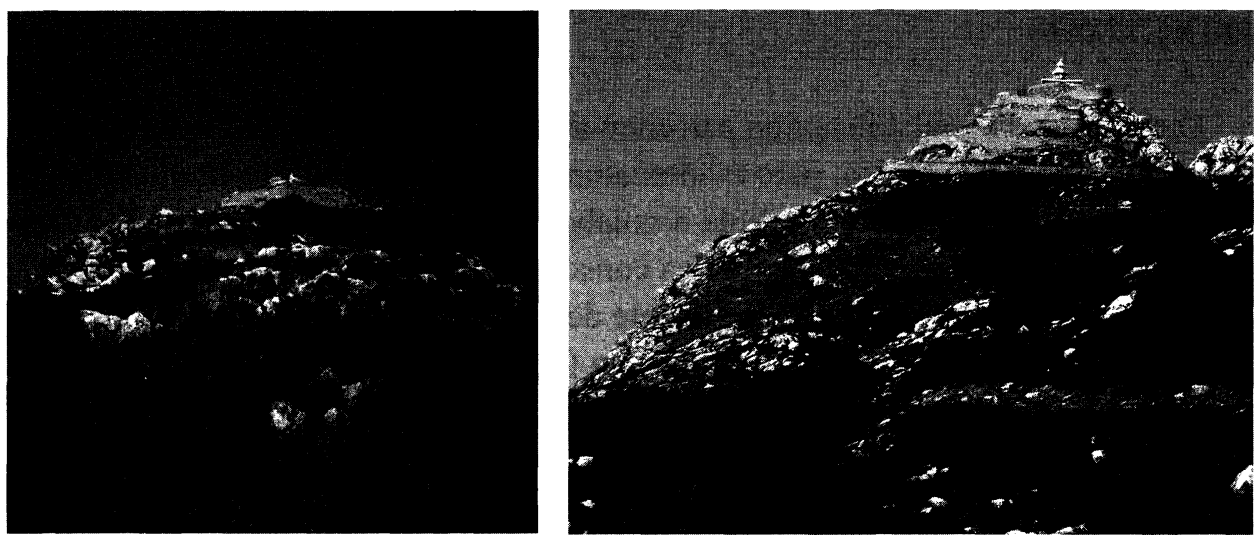

Vistas xerais do xacemento antes e despois da limpeza da vexetación.

as razóns de situar eiquí a acrópole do asentamento son a visibilidade, a defensibilidade (totalmente imposible nun asentamento de media ladeira) e os restos dun probable foxo ó E do faro. Na ladeira quedarían por tanto o basureiro do poboado, materiais de arrastre e estructuras habitacionais dispersas por extramuros. Os restos de casas e socalcos corresponderían ós labregos dependentes do mosteiro de Sto. Estevo ${ }^{6}$ e que comenzaron a reconoliza-la illa a partires da Baixa Idade Media. Si ben a limpeza aporta luces tamén nos presenta novas dúbidas como as de saber si os socalcos poden ter unha orixe romana ou son todos da Idade Moderna, polo que serían precisos máis estudios tendentes a clarificar e contextualiza-lo xacemento.

Os obxetivos científicos futuros poden ser os de determinar a veracidade das supostas relacións destas illas co comercio do estaño na Idade do Ferro e o análise polínico dos paleo-solos para determina-la flora orixinal das illas na antigüidade o que evidentemente resulta de moito interés para os biólogos.

Por último e en canto ós obxectivos educativos do proxecto, verdadeiro motor desta iniciativa, non somos os indicados para avalia-lo seu éxito, xa o fixeron os propios acampados nas súas fichas de avaliación e os directores dos equipos de tempo libre nos seus informes. Simplemente mentar que se ofreceron certificados de participación que foron reclamados pola práctica totalidade dos participantes, na maioría dos casos non por que os precisasen para os seus curricula, senón por que querían algo que demostrase a súa participación nun proxecto do que estaban orgullosos.

\footnotetext{
${ }^{6}$ Dase a casualidade que nesta illa existiu outro mosteiro co mesmo nome que o de Nogueira de Ramuín.
}

Cuadernos de Estudios Gallegos, Tomo LI, Fascículo 117, Santiago 2004. (Págs. 115 - 132) 
O indudable éxito da campaña se debe fundamentalmente á excelente simbiose do equipo de arqueoloxía cos equipos de animación e tempo libre, sen esquece-la labor dos compañeiros de cociña, a imprescindible e perfecta coordinación da xerencia do campo de traballo e o apoio «máis ala do deber» por parte da Xefatura de Servicios da Dirección Xeral de Xuventude, para todos o noso sinceiro agradecemento, eles xunto cos voluntarios foron a nosa motivación.
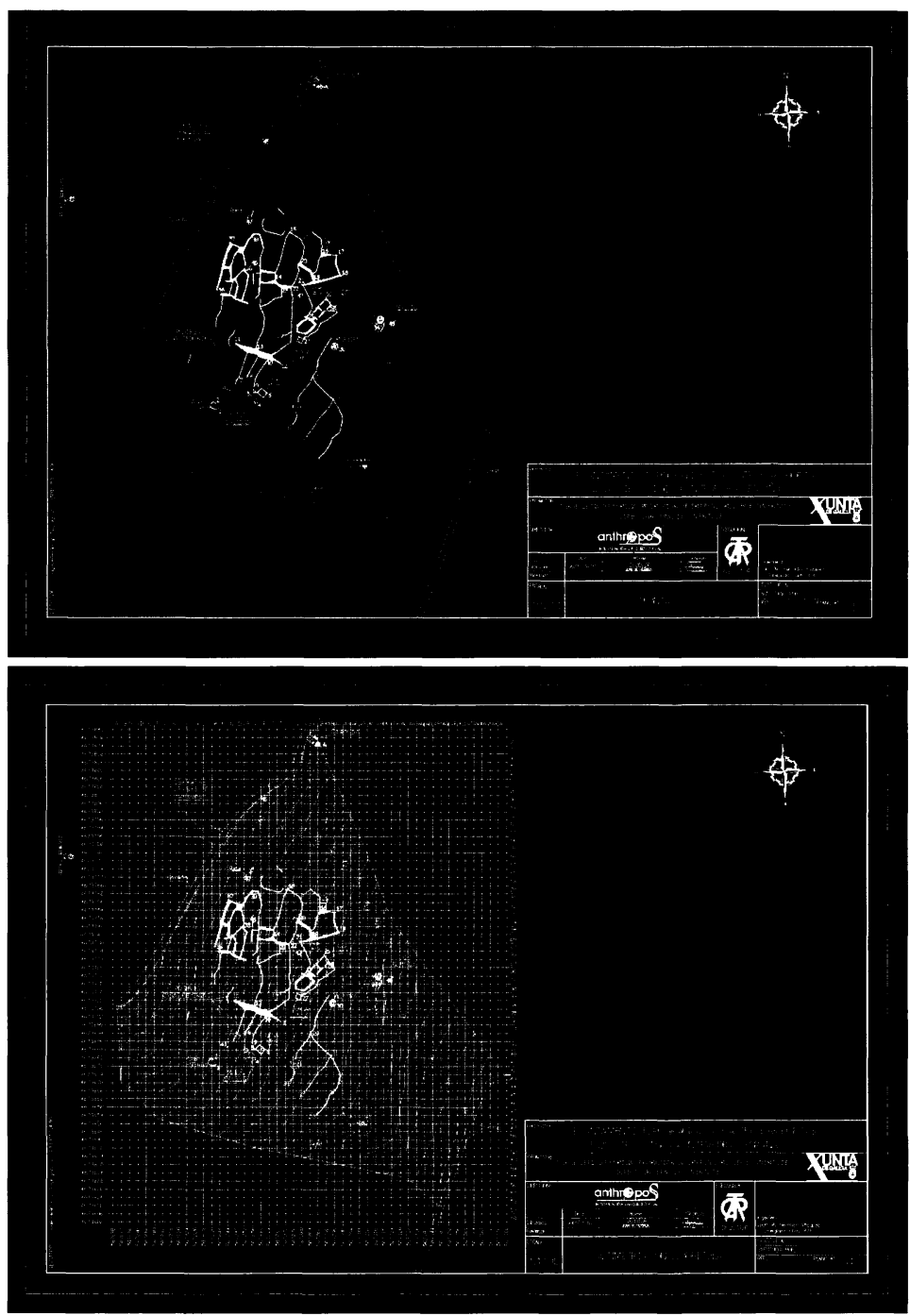

Planimetría do xacemento. 


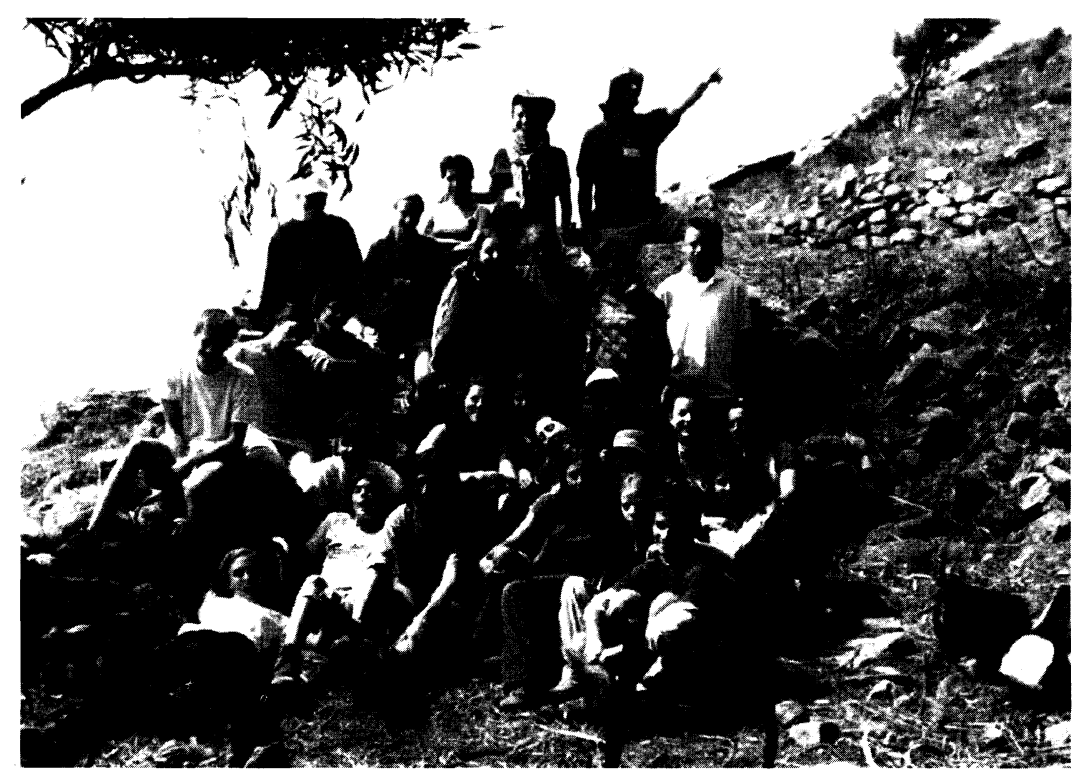

Foto de grupo da $3^{\mathrm{a}}$ quenda. 


\section{BIBLIOGRAFÍA}

ARIAS SANJURJO, J. 1913-18. «Una excursión a la Ribeira Sagrada». Boletín de la Comisión de Monumentos de Orense, 41-47, Ourense.

BLANCO, X.A. \& RODRÍGUEZ, X. M. 1991. «Localización do emplazamento do Castelo de Litoria». O Rumor da Fraga, 1, Ourense.

BLANCO, X. A., DORRIBO, X. R. \& RODRÍGUEZ, X. M. 1992. «Coto de Santo Estevo (Nogueira de Ramuín)». O Rumor da Fraga, 3, Ourense.

CARBALlO ARCEO, X., LUACES ANCA, J., TOSCANO NOVELLA, Mª C. 1998. Arqueoloxía de Vigo e a súa História, Catálogos do Patrimonio, Concello de Vigo.

CASAL GARCÍA, R., EGUILETA FRANCO, J. Ma, GARCÍA VALDEIRAS, M. e ROMANÍ FARIÑA, E. 1997. Nogueira de Ramuín, Natureza, Ocio, Cultura. Concello de Nogueira de Ramuín.

CURT, J. 1989. Mis Cies, tus Cies, nuestras Cies. Vigo.

DURO PEÑA, E. 1977. El Monasterio de San Esteban de Ribas de Sil. Ourense.

DURO PEÑA, E. e PLATERO PAZ, J. 1990. Historia, arte y entorno del monasterio de San Esteban de Ribas de Sil. Obra Cultural Caixa Ourense, León.

CHAMOSO LAMAS, M. e PONS-SOROLLA, F. 1963. «El monasterio de San Esteban de Ribas de Sil y su retablo de piedra». Cuadernos de Estudios Gallegos, XIII, Santiago de Compostela.

EGUILETA FRANCO, J. Ma., (Coord). 1999. Nogueira de Ramuín. Ourense.

EGUILETA FRANCO, J. Ma . e GARCÍA VALDEIRAS, M. 1998. «Concello de Nogueira de Ramuín. Unha porta da Ribeira Sacra». Auria, 13, Ourense.

FERRO COUSELO, J. Los petroglifos de término y las insculturas rupestres de Galicia. Ourense.

FREIRE CAMANIEL, J. 1988-89. «¿Un testimonio epigráfico de la existencia, en Orense, de un «Duque» de Leovigildo?». Boletín Auriense, XVIII-XIX, Ourense.

GARCÍA VALDEIRAS, M. 2001. Escavación arqueolóxica nos Penedos do Castro (Nogueira de Ramuin, Ourense) Informe Valorativo da $3^{\text {a }}$ fase depositado na D.X.P.C.

GARCÍA VALDEIRAS, M. 2002. Escavación arqueolóxica nos Penedos do Castro (Nogueira de Ramuín, Ourense) Proxecto da $4^{\mathrm{a}}$ fase depositado na D.X.P.C.

GARCÍA VALDEIRAS, M. 2002. Rendabilización socio-cultural do Castro das Cies (Vigo, Pontevedra) Informe Valorativo depositado na D.X.P.C.

GUTIÁN RIVERA, F., VÁZQUEZ VARELA, J. M. 1979. «Sobre la tecnología de la cerámica castreña (Cerámica de las Islas Cíes. Pontevedra)», Gallaecia 3/4. Santiago de Compostela, pp. 275-279.

MARTÍNEZ SUEIRO, M. 1914. «La Ribeira Sagrada». Boletín de la Comisión. de Monumentos de Orense, 1913-18, Ourense.

PAZOS RODRÍGUEZ, O. 1992. «Estudio geológico de las Islas Cíes». Memoria de la prospección arqueológica de las Islas Cíes. Concello de Vigo-Xunta de Galicia, Vigo (inédito).

Cuadernos de Estudios Gallegos, Tomo LI, Fascículo 117, Santiago 2004. (Págs. 115 - 132) 
PEÑA SANTOS de la, A. 1999. "A perspectiva actual sobre as orixes da cidade» en Historia de Vigo. A Coruña, pp.42-85.

PLATERO PAZ, J. 1998. «San Esteban de Ribas de Sil (I). El monasterio: armonía en la Diversidad». Auria, $n^{\circ} 19$, Ourense.

REY CASTIÑEIRA, J. 1992. «Cerámica indígena de los castros costeros de la galicia occidental : Rías Bajas. Valoración dentro del contexto general de la cultura castreña», Revista Castrelos, 34, pp. 141-163.

REY CASTIÑEIRA, J. 1992. «Estudio de materiales cerámicos». Memoria de la prospección arqueológica de las Islas Cíes. Concello de Vigo-Xunta de Galicia, Vigo (inédito).

RODRÍGUEZ COLMENERO, A. 1995. «Corpus de inscripciones rupestres de época romana del cuadrante Noroeste de la península Ibérica». En COLMENERO, A. \& GASPERINI, L. (Eds.), Saxa Scripta (Inscripciones en Roca). Actas do Simposio Internacional Ibérico Itálico sobre epigrafía rupestre. Anejos Larouco 2.

TOSCANO NOVELLA, C., LUACES ANCA, J., ALEMPARTE PUGA, L. 1992. GA36057080. Castro das Hortas, Ficha de catalogación depositada na D.X.P.C.

TOSCANO NOVELLA, Mª C. e LUACES ANCA, J. 1992. «Memoria de la prospección arqueológica de las Islas Cíes». Concello de Vigo-Xunta de Galicia, Vigo (inédito).

VÁZQUEZ VARELA, J. M. 1975. «Estudio del conchero protohistórico de las Islas Cíes. Vigo», Actas de las I Jornadas de Metodología Aplicada a las Ciencias Históricas, I. Prehistoria e Historia antigua, Santiago de Compostela, pp. 291-295.

VÁZQUEZ VARELA, J. M. 1976. «Bases paleontológicas para el estudio de la pesca en la cultura castreña: una investigación preliminar», Boletín Auriense, VI. Orense, pp. 83-86.

XUNTA DE GALICIA. 2002. Campaña de verán 2002. Catálogo de campos de traballo elaborado pola Dirección Xeral de Xuventude. 